\title{
Depression and anxiety symptoms in pregnant women in Denmark during COVID-19
}

Gritt Overbeck ${ }^{1}$, Ida Scheel Rasmussen ${ }^{1}$, Volkert Siersma ${ }^{1}$, Julie Høgsgaard Andersen ${ }^{1}$, Jakob

Kragstrup $^{1}$, Philip Wilson ${ }^{1,2}$, Anette Hauskov Graungaard ${ }^{1}$, Ruth Kirk Ertmann ${ }^{1}$

${ }^{1}$ The Research Unit for General Practice and Section of General Practice, Department of Public Health, University of Copenhagen, Copenhagen, Denmark gen

${ }^{2}$ Centre for Rural Health, Institute of Applied Health Sciences, University of Aberdeen, Scotland

Corresponding author and author to request offprints from:

Gritt Overbeck

Section of General Practice, Dept. of Public Health

University of Copenhagen

Øster Farimagsgade 5

DK- 1014 Copenhagen K

Denmark 


\begin{abstract}
Aims. Maternal mental distress in pregnancy can be damaging to the mother and child's physical and mental health. This study aimed to provide insight into mental wellbeing of pregnant women in Denmark during COVID-19, by assessing symptoms of depression and anxiety.
\end{abstract}

Methods. Data from two cohorts of pregnant women recruited from Danish general practice were compared. A COVID-19 lockdown cohort ( $\mathrm{n}=330)$ completed questionnaires between April 8th and May 6th. Responses were compared to those from a control cohort of women from 2016 ( $n=1428)$. Mental wellbeing was measured with the Major Depression Inventory (MDI) and the Anxiety Symptom Scale (ASS).

Results. Questionnaires were returned by $83 \%$ of the COVID-19 lockdown cohort and by $93 \%$ of the control cohort. A multivariable analysis controlling for age, cohabitation status, occupation, smoking, alcohol use, chronic disease, fertility treatment, parity and children living at home showed no difference in depressive symptoms (MDI). Anxiety symptoms (ASS) were slightly worse in the COVID-19 lockdown cohort (mean difference 1.4 points), mainly driven by questions concerning general anxiety. The largest differences in anxiety were seen in first trimester (adjusted mean difference: 4.0 points).

Conclusion. Pregnant women questioned during COVID-19 showed no change in symptoms of depression and only a modest elevation of anxiety when compared to pregnant women questioned during a nonpandemic period in 2016.

Keywords: Anxiety; COVID-19 Pandemic; depression; Mental Health; Pregnancy; Prenatal Care

Word count for manuscript, excl. abstract, references and tables: 2,663 


\title{
Introduction
}

As the coronavirus pandemic sweeps across the world, it may induce fear and stress. Added to the fear of contracting the virus are the significant changes to our daily lives, as quarantine and social distancing measures are implemented to slow down the spread of the virus. Worrying about family and friends being infected may also be a burden. It is, therefore, not surprising that reviews of early studies of mental health in the pandemic have revealed lower psychological well-being and higher scores of depression and anxiety in the general public compared to before COVID-19 ${ }^{12}$.

Studies on COVID-19 and adverse pregnancy consequences have been published recently, mostly investigating respiratory-related outcomes in the pregnant woman and the neonate. The impact of the pandemic on maternal mental health has received less attention ${ }^{3}$. Mental distress during pregnancy, however, is a major public health concern. Stressful events are associated with adverse outcomes for the mother as well as the child; possible negative effects include premature delivery ${ }^{4}$, disrupted mother-child attachment ${ }^{5,6}$, and adverse developmental outcomes in the child, including increased risk of emotional and behavioural problems, ${ }^{7,8,9}$. A single study comparing mental health in pregnant women before and during COVID-19 has shown increased levels of distress during COVID- $19^{10}$, which raises concern.

\begin{abstract}
Aims
Our study aimed to provide insight into the mental wellbeing of pregnant women's in Denmark during COVID-19 by assessing symptoms of depression and anxiety.
\end{abstract}

\section{Methods}

The study compared depression and anxiety symptoms in a sample of pregnant women during COVID-19 lockdown with symptoms in a control sample from 2015-16. 
Setting

On March $11^{\text {th }}, 2020$, the World Health Organisation (WHO) declared COVID-19 a global pandemic with 110,000 confirmed cases of virus infection in 110 countries. The previous day, Denmark had 157 confirmed cases and on March $11^{\text {th }}$ the government announced that this number had increased to 514 and responded with a lockdown from the $12^{\text {th }}$ of March. Schools and daycare centers were closed; employees in the public sector were sent home and only people working in critical functions maintained a physical presence at work. The government also urged Danish private-sector employers to ask their employees to work from home. Danish employment insurance funds reported an increase of 39\% in unemployment in early May, despite a late March agreement on a temporary salary compensation to protect private companies and their employees. The social life of the population was affected too; sports, leisure activities, cinemas, etc. were locked down, while gatherings of more than 10 people were prohibited, and large shops and malls were closed. Danish authorities encouraged social distancing but never instituted a curfew or mandated face masks as seen in some other countries. A gradual re-opening began in mid-April, starting with daycare, schools and the private labour market.

Danish National Health Services regarded preventive antenatal programmes as high priority, and preventive consultations were not paused during lockdown ${ }^{11}$. The preventive health services in general practice and midwifery adapted to the situation by re-structuring some of the appointments to video consultations. At the same time, fathers/partners were not allowed to join e.g. ultrasound examinations.

\section{Participants}

This study compared the mental wellbeing of two groups of pregnant women; one group which was pregnant before lockdown (in 2016) and one group which was pregnant during lockdown in 2020. The participating pregnant women in both groups had been recruited by general practitioners (GPs) in Capital Region and 
Region Zealand (two of the five administrative regions in Denmark) at the first preventive antenatal consultation occurring around 10 weeks' gestation. None of the groups received interventions for depression or anxiety. The preventive antenatal consultation is free of charge and almost all pregnant women attend. The participating general practitioners were asked to consecutively include all Danish-speaking pregnant women. Women who participated gave informed consent to provide data from the pregnancy record and questionnaires. Women were excluded if they withdrew consent or if the pregnancy ended in abortion or stillbirth. Details of the two cohorts are given below.

The COVID-19 lockdown cohort included pregnant women enrolled in an existing cluster randomized trial of an online psycho-educational program. Recruitment started in 2019 and participants who had not given birth by April $8^{\text {th }}, 2020$ were included in this study. They had given informed consent to take part in a project focusing on quality improvement of preventive mother-child consultations in general practice, and on the mental health of small children and their families ${ }^{12}$. Half of the participating general practitioners would inform their patients about a web-based program to increase resilience in families. All included women who were still pregnant on April $8^{\text {th }}, 2020$ - four weeks after the lockdown began - were sent a questionnaire. One reminder was sent after 2 weeks and all answers received before May $6^{\text {th }}$ were included in the study. A secure electronic mail system (e-Boks) was used to inform participants about the survey, and questionnaires were completed and returned into the study database (REDCap).

The control cohort. A similar cohort from April 2015 was used as control, here 192 general practitioners included pregnant women at their first antenatal appointment ${ }^{13}$. Women gave informed consent to taking part in a general quality improvement study. Data were obtained until August 2016 and all participating pregnant women were sent three questionnaires at around gestational weeks 10, 26 and 33, including questions about depressive symptoms (Major Depression Inventory - MDI ${ }^{14,15}$ ) and anxiety (Anxiety Symptom Scale - ASS ${ }^{16}$ ). Questionnaires were answered by means of SurveyXact and reminders were sent for each questionnaire. 
Outcomes. The Major Depression Inventory (MDI) is a self-reported instrument consisting of ten items each with a Likert scale ranging from 0 ("at no time") to 5 ("all the time"), giving a range of 0-50 in the total score. Used as a depression severity scale the cut-off scores are 0-20 (no or doubtful depression), 21-25 (mild depression), 26-30 (moderate depression), and 31-50 (severe depression) ${ }^{13,14}$.

The Anxiety Symptom Scale (ASS) screens for anxiety symptoms and can be used as an initial method to ascertain anxiety. ASS is a self-reported instrument and is recommended by the Danish College of General Practitioners ${ }^{16}$. The ten ASS items include general anxiety (items 1-2), avoidance behavior (item 3), panic attacks (items 4-5), OCD symptoms (items 6-8) and post-traumatic anxiety (item 9). Item 10 covers level of functioning. Each item ranges from 0 (no anxiety symptoms) to 5 (anxiety symptoms occurring all the time) which gives a total ASS score with a range between 0-50 ${ }^{14}$. Since ASS was not primarily devised as an outcome measure for clinical scientific inquiry, its psychometric properties were not investigated and are as yet unknown. We therefore investigated the responses to the individual items in a secondary analysis.

Covariates. Information was collected from the Pregnancy Health Record and from an electronic patient questionnaire. The Pregnancy Health Record is a national two-page form, which was filled by the GP and sent to the midwife as well as the expected place of birth. In this study the following parts of the record were used: Sociodemographic: Age ( $\leq 25,26-30,31-35,>35)$, Cohabitation status (single/ living with partner). Lifestyle habits: Smoking during pregnancy (yes/no), Alcohol during pregnancy (yes/no), Recreational drugs during pregnancy (yes/no). Physical health: heart disease, lung disease, thyroid disease, diabetes, epilepsy, psychiatric disorder (no/yes). Reproductive background: Fertility treatment (yes/no), Parity: Given birth (no/ yes, one/ yes, several times), Miscarriage (no/ yes, one/ yes, several times). The electronic patient questionnaire contained Occupational status (employed/student/ other/ unemployed/ sick leave) and Children living at home (no/yes).

The women in the control group 


\section{Statistical analysis}

Differences in the distribution of covariates between the two cohorts were assessed by chi-squared tests. The difference in mean outcome between the two cohorts was assessed in multivariable linear regression models. The women in the control were asked to fill the questionnaire each trimester, and we therefore had up to three per woman;

while the women of the Covid-19 lockdown cohort completed the questionnaire only once during their pregnancy. The statistical analysis corrected for this excess correlation of assessments in the control group by including a random effect in the mixed linear model. The differences were adjusted only for trimester (unadjusted), or adjusted additionally for age, cohabitation status, occupation, smoking, alcohol- and drug use, fertility treatment, previous abortions and children living at home. Additionally, in subgroup analyses the cohort effect was assessed in similar fashion for the categories of a selection of covariates. Statistical significance was set at 1\%. Calculations were performed in SAS v9.4.

\section{Ethics}

Women included in both cohorts gave written consent for researchers to access data from their Pregnancy Health Record and to allow questionnaires about mental well-being to be sent.

\section{Results}

ASS and MDI were sent to 330 pregnant women in 2020 during COVID-19 lockdown. The COVID-19 lockdown cohort comprised 33 women in the first trimester of pregnancy (weeks 0-12), 219 in the second trimester and 78 in the third trimester .Two hundred and fifty three (83\%) were completed. ASS and MDI were sent to 1428 pregnant women in 2016 and were completed by 1428 in the first trimester (100\%), by 1343 women in the second trimester $(94 \%)$ and by 1326 women $(93 \%)$ in the third trimester. 
Table I shows the characteristics of the women in the two cohorts. The only statistically significant difference between the groups was related to the number of previous births, but the fraction that had not given birth previously was almost the same in the two groups (45\% in the control group versus $43 \%$ in the Covid-19 lockdown group).

Table II and III show MDI and ASS scores for the pregnant women during COVID-19 lockdown compared to the control group from 2016. No significant difference in MDI was observed, while ASS was somewhat higher during lockdown. The difference in total ASS score (1.4 points) remained statistically significant after adjusting for potential confounding. The difference in anxiety symptoms varied across trimesters; the largest difference was seen in the first trimester ( 4 points), followed by the third trimester with a difference of 2 points. Subgroup analyses did not show significant differences in MDI or ASS between categories of selected covariates.

Table IV shows the results for the individual ASS items. We observed higher levels of general anxiety (items 1 and 2) and avoidance behavior (item 3) but lower social phobia (item 8) in the COVID-19 lockdown cohort, while for the other items no substantial difference was observed.

\section{Discussion}

We found no changes in depressive symptoms among pregnant women during the early phase of COVID-19 lockdown in the Danish society. The level of anxiety was higher during lockdown with an average difference between the two cohorts of 1.4 point on a scale from 0 to 50 .

Our unique opportunity to compare data from two similar cohorts of women made it possible to assess the association between antenatal mental health and the lockdown. It is, however, important to consider the ways in which these two cohorts may be different apart from the pandemic. Secular trends may themselves produce changes, but the period (4 years) is relatively short, and we are not aware of any major changes in the situation of pregnant women in Denmark over these years apart from the lockdown. The sampling of the 
women for the two groups was in many ways similar. They were recruited into the two cohorts by their general practitioners, and the women gave informed consent to participate in a study where they would receive questionnaires several times during their pregnancy. The present analysis was, however, of convenience and sampling of the two cohorts was not designed for the present purpose. The Covid-19 lockdown cohort comprised a relatively small group of women, which made statistical analysis less powerful. There was, furthermore, a difference in response rates between the two cohorts, which was due to the nature of the projects behind the two samples. The 2016 control group was a dedicated cohort followed during pregnancy and much effort was put into collecting each questionnaire. The COVID-19 group received fewer reminders, because the project needs to follow the women for several years without overloading the participants. The use of the mixed model corrects, however, for bias through differential attrition, when this is related to the variables (such as sociodemographic characteristics) that are in the model. None of the groups received interventions aimed at symptoms of depression or anxiety but half of the women in the lockdown group had access to an intervention which aimed at improving psychological resilience in general. Any effect of this intervention may have reduced ASS in the COVID-19 lockdown cohort and decreased the difference compared to the control group. There have been recent preliminary reports about pregnant women's mental wellbeing during the pandemic ${ }^{17} 1920$. A Canadian study of pregnant women from May 2020 contrasted antenatal maternal stress during COVID-19 with symptoms in a cohort of women before the pandemic. This study found an upsurge in both depressive and anxiety symptoms in pregnant women during COVID-19 ${ }^{10}$. A survey of mental wellbeing in pregnant women and new mothers during the pandemic found similar signs of increased symptoms of depression and anxiety ${ }^{21}$. Similarly, a number of general population studies have found an increase of depressive as well as anxiety symptoms, while we only found enhanced anxiety symptoms in pregnant Danish women. Methodological differences may be part of the explanation, but national differences may also be important: The majority of published papers about mental wellbeing in the COVID-19 pandemic are from China and other countries that were infected early and had harsh lockdowns ${ }^{12}$; recently published studies of general population mental well-being in Denmark and Norway during the lockdown period in spring 2020 did not find an upsurge in mental distress ${ }^{22} 23$. 
Several explanations for the pandemic's apparently low impact on mental wellbeing in pregnant women could be offered, including the fact that Denmark never faced a curfew such as that seen in some other countries. In addition, shops were open and people were free to move around in public as long as a safe distance was kept from others. Primary care and hospitals were also never overwhelmed with patients; this fact was repeatedly communicated by authorities through national TV with high viewing figures, reaching almost half of the population. Pregnant women are well protected against dismissal during pregnancy and can be absent with compensation; for some pregnant women the lockdown may have been an opportunity for more stable circumstances at home. A survey in the general population saw the psychological well-being of the Danish population apparently improving from early spring to the end of April ${ }^{22} 24$.

A pandemic and the subsequent societal changes during spring 2020 might be expected to impact mental health in pregnant women more than our results show. The virus itself may not have impacted public mental health substantially because the health threat rapidly turned out to be low. Any negative impact on mental wellbeing may very well rather come from the societal and economic consequences of locking down society. This could lead to economic depression in the longer term. It is, therefore, important to monitor the mental well-being of pregnant women for a longer period of time. Future studies should also look into how the pandemic and lockdown might have had differential effects on families from varying backgrounds: the two cohorts of pregnant women in this study represented a socioeconomically rather privileged group that could not be regarded as vulnerable.

\section{Conclusion}

COVID-19 and the lockdown led to sudden societal changes not seen in Denmark since World War II. In spring 2020, the crisis did not have any immediate strong effect on the mental wellbeing of pregnant women in Denmark when significantly elevated levels of depression and anxiety among Danish pregnant women during COVID-19 lockdown might have been expected. At this early point of the pandemic, pregnant women appeared to be only moderately more anxious compared to pregnant women during a non-COVID-19 
period. The full-scale consequences of the pandemic crisis are not known yet and should be carefully monitored. 


\section{Acknowledgements}

The authors would like to thank the funders for the financial support. Professor Kaj Sparle Christensen advised regarding interpretation of anxiety symptom scale.

\section{Declaration of Conflicting Interests}

The Authors declare that there is no conflict of interest.

\section{Funding}

This work was supported by TRYGfonden [grant number 125227] and the quality and continuing education committee for general practice in the Capital Region [grant number 19035774]. 


\section{References}

1. Wang C, Pan R, Wan X, Tan Y, Xu L, Ho CS et al. Immediate Psychological Responses and Associated Factors during the Initial Stage of the 2019 Coronavirus Disease (COVID-19) Epidemic among the General Population in China. Int J Environ Res Public Health 2020 Mar; 17 2020/03/12. DOI: 10.3390/ijerph17051729.

2. Vindegaard N and Benros ME. COVID-19 pandemic and mental health consequences: Systematic review of the current evidence. Brain Behav Immun 2020 oct; 89: 531-542. DOI: 10.1016/j.bbi.2020.05.048.

3. Thapa SB, Mainali A, Schwank SE, Acharya G. Maternal mental health in the time of the COVID-19 pandemic. Acta Obstet Gyn Scan 2020 Jul; 99: 817-818. DOI: 10.1111/aogs.13894.

4. Lilliecreutz C, Larén J, Sydsjö G, Josefsson. Effect of maternal stress during pregnancy on the risk for preterm birth. BMC Pregnancy Childbirth 2016 Jan; 16: 5. DOI: 10.1186/s12884-015-0775-x.

5. Pearson RM, Melotti R, Heron J, Joinson C, Stein A, Ramchandani PG, Evans J. Disruption to the development of maternal responsiveness? The impact of prenatal depression on mother-infant interactions. Infant Behav Dev 2012 Dec; 35: 613-626. 2012/09/18. DOI: 10.1016/j.infbeh.2012.07.020.

6. Blackmore ER, Gustafsson H, Gilchrist M, Wyman C, O'Connor TG. Pregnancy-related anxiety: Evidence of distinct clinical significance from a prospective longitudinal study. J Affect Disord 2016 Jun; 197: 251-258. 2016/03/08. DOI: 10.1016/j.jad.2016.03.008.

7. Talge NM, Neal C, Glover V. Antenatal maternal stress and long-term effects on child neurodevelopment: how and why? J Child Psychol Psychiatry. 2007 Mar-Apr;48(3-4):245-61. DOI: 10.1111/j.1469-7610.2006.01714.x [published Online First: 2007/03/16

8. Tough SC, Siever JE, Leew S, Johnston DW, Benzies K, Clark D. Maternal mental health predicts risk of developmental problems at 3 years of age: follow up of a community based trial. BMC Pregnancy Childbirth 2008 May; 8: 16. 2008/05/08. DOI: 10.1186/1471-2393-8-16. 
9. Hunter AL, Minnis H and Wilson P. Altered stress responses in children exposed to early adversity: a systematic review of salivary cortisol studies. Stress 2011 Nov; 14: 614-626. 2011/06/17. DOI: 10.3109/10253890.2011.577848.

10. Berthelot N, Lemieux R, Garon-Bissonnette J, Drouin-Maziade C, Martel É, Maziade M. Uptrend in distress and psychiatric symptomatology in pregnant women during the coronavirus disease 2019 pandemic. Acta Obstet Gynecol Scand 2020 Jul; 99: 848-855. 2020/05/26. DOI: 10.1111/aogs.13925.

11. Danish National Board of Health. Critical functions in health care during COVID-19 [Håndtering af COVID-19: Beskrivelse af kritiske funktioner i sundhedsvæsnet under COVID-19], 2020. Available from: https://www.sundhed.dk/content/cms/98/111798 beskrivelse kritiske funktioner.pdf (2020, accessed 15 August 2020, ).

12. ClinicalTrials.gov. FamilieTrivsel i Almen Praksis: a Mentalisation Programme for Families With Young Children. 2019. Available from https://www.clinicaltrials.gov/ct2/show/NCT04129359?term=wilson\&cntry=DK\&draw=2\&rank=4 (2019, accessed 22 January 2021).

13. Ertmann RK, Nicolaisdottir DR, Kragstrup J, Siersma V, Lutterodt MC, Bech P. Physical discomfort in early pregnancy and postpartum depressive symptoms. Nord J Psychiatry 2019 Apr; 73: 200-206. 2019/03/09. DOI: 10.1080/08039488.2019.1579861.

14. Bech P. Clinical Psychometrics. Oxford. John Wiley \& Sons, Ltd; 2012.

15. Bech P, Timmerby N, Martiny K, Lunde M, Soendergaard S.Psychometric evaluation of the Major Depression Inventory (MDI) as depression severity scale using the LEAD (Longitudinal Expert Assessment of All Data) as index of validity. BMC psychiatry 2015 Aug; 15: 190-190. DOI: 10.1186/s12888-015-0529-3.

16. Sparle K. Angststilstande [Anxiety conditions]. Danish College of General Practitioners, 2010. Available from: https://vejledninger.dsam.dk/angst/. (2012, accessed 14 August 2020)

17. Davis-Floyd R, Gutschow K and Schwartz DA. Pregnancy, Birth and the COVID-19 Pandemic in the United States. Medical Anthropol. 2020 Jul; 39: 413-427. DOI: 10.1080/01459740.2020.1761804. 
18. Verbeke G, Molenberghs G. Linear Mixed Models for Longitudinal Data. Springer Ser Stat; 2009:1568.

19. Durankuş F and Aksu E. Effects of the COVID-19 pandemic on anxiety and depressive symptoms in pregnant women: a preliminary study. J Matern Fetal Med 2020 May: 1-7. DOI: 10.1080/14767058.2020.1763946.

20. Lebel C, MacKinnon, A., Bagshawe, M., Tomfohr-Madsen, L., \& Giesbrecht, G. Elevated depression and anxiety among pregnant individuals during the COVID-19 pandemic. J Affect Disord. 2020 Dec 1; 277: 5-13. DOI: 10.1016/j.jad.2020.07.126.

21. Davenport MH, Meyer S, Meah VL, Strynadka MC, Khurana R. Moms Are Not OK: COVID-19 and Maternal Mental Health. Front. Glob. Women's Health 2020 June; 1. Original Research. DOI: 10.3389/fgwh.2020.00001.

22. Clotworthy A, Dissing AS, Nguyen T-L, et al. 'Standing together - at a distance': Documenting changes in mental-health indicators in Denmark during the COVID-19 pandemic. Scand J Public Health 2020. DOI: $10.1177 / 1403494820956445$

23. Harris, S. M., \& Sandal, G. M. (2020). COVID-19 and psychological distress in Norway: The role of trust in the healthcare system. Scand J Public Health 2020. DOI: 10.1177/1403494820971512

24. Sønderskov KM, Dinesen PT, Santini ZI, Østergaard SD. Increased Psychological Well-being after the Apex of the COVID-19 Pandemic. Acta Neuropsychiatr. 2020 Jul: 1-8. 2020/07/06. DOI: 10.1017/neu.2020.26. 
Table I: Characteristics of participating women in the 2016 cohort (control) and COVID-19 lockdown cohort.

\begin{tabular}{|c|c|c|c|}
\hline & $\begin{array}{l}\text { Control cohort from } 2016 \\
(\mathrm{n}=1428)\end{array}$ & $\begin{array}{l}\text { COVID-19 lockdown cohort } \\
(\mathrm{n}=330)\end{array}$ & \\
\hline & $\mathrm{N}(\%)$ & $\mathrm{N}(\%)$ & Sign. \\
\hline Age & & & 0.1604 \\
\hline$\leq 25$ years & $180(12.6)$ & $28(8.5)$ & \\
\hline 26-30 years & $491(34.4)$ & $122(37.0)$ & \\
\hline $31-35$ years & $480(33.6)$ & $120(36.4)$ & \\
\hline$>35$ years & $277(19.4)$ & $60(18.1)$ & \\
\hline Cohabitation status & & & 0.6188 \\
\hline Single & $71(5.0)$ & $17(5.7)$ & \\
\hline Living with partner & $1357(95.0)$ & $283(94.3)$ & \\
\hline Children living at home & & & 0.8977 \\
\hline No & $590(41.3)$ & $123(40.9)$ & \\
\hline Yes & $838(58.7)$ & $178(59.1)$ & \\
\hline Occupation & & & 0.2488 \\
\hline Employed & $1069(74.9)$ & $242(73.8)$ & \\
\hline Student & $197(13.8)$ & $51(15.6)$ & \\
\hline Other & $61(4.3)$ & $9(2.7)$ & \\
\hline Unemployed & $75(5.3)$ & $15(4.6)$ & \\
\hline Sick leave & $26(1.8)$ & $11(3.4)$ & \\
\hline Smoking during pregnancy & & & 0.0882 \\
\hline No & $1331(93.2)$ & $288(96.0)$ & \\
\hline Yes & $97(6.8)$ & $12(4.0)$ & \\
\hline Alcohol during pregnancy & & & 0.9630 \\
\hline No & $1418(99.3)$ & $294(99.3)$ & \\
\hline Yes & $10(0.7)$ & $2(0.7)$ & \\
\hline Recreational drugs during pregnancy & & & 0.2671 \\
\hline No & $1424(99.7)$ & $287(99.3)$ & \\
\hline Yes & $4(0.3)$ & $2(0.7)$ & \\
\hline Chronic heart disease & & & 0.3859 \\
\hline No & 1365 (95.6) & $312(94.6)$ & \\
\hline Yes & $63(4.4)$ & $18(5.4)$ & \\
\hline Chronic lung disease & & & 0.3479 \\
\hline No & $1328(93.0)$ & $302(91.5)$ & \\
\hline Yes & $100(7.0)$ & $28(8.5)$ & \\
\hline Thyroid disease & & & 0.2524 \\
\hline No & $1372(96.1)$ & $322(97.6)$ & \\
\hline Yes & $56(3.9)$ & $8(2.4)$ & \\
\hline Diabetes & & & 0.7200 \\
\hline No & $1418(99.3)$ & $327(99.1)$ & \\
\hline Yes & $10(0.7)$ & $3(0.9)$ & \\
\hline Epilepsy & & & 0.2430 \\
\hline No & $1414(99.0)$ & $324(98.2)$ & \\
\hline Yes & $14(1.0)$ & $6(1.8)$ & \\
\hline Psychiatric disorder & & & 0.8128 \\
\hline No & $1324(92.7)$ & $308(93.3)$ & \\
\hline Yes & $104(7.3)$ & $22(6.7)$ & \\
\hline Fertility treatment & & & 0.8335 \\
\hline No & $1288(90.2)$ & $284(90.7)$ & \\
\hline Yes & $140(9.8)$ & $29(9.3)$ & \\
\hline Given birth & & & 0.0012 \\
\hline No & $645(45.2)$ & $136(43.0)$ & \\
\hline Yes, one & $530(37.1)$ & $146(46.2)$ & \\
\hline Yes, several & $253(17.7)$ & $34(10.8)$ & \\
\hline Previous abortion & & & 0.3945 \\
\hline No & $892(62.5)$ & $187(59.2)$ & \\
\hline Yes, one & $367(25.7)$ & $93(29.4)$ & \\
\hline Yes, several & $169(11.8)$ & $36(11.4)$ & \\
\hline
\end{tabular}


Table II: Depression symptoms assessed by Major Depression Inventory (MDI-score) in the COVID-19 lockdown cohort compared to the control cohort from 2016.

\begin{tabular}{|c|c|c|c|c|c|c|c|c|}
\hline & Control cohort from 2016 & COVID-19 lockdown cohort & Unadjusted & & & Adjusted & & \\
\hline & Mean (SD) & Mean (SD) & Mean diff. $(95 \% \mathrm{CI})$ & Sign. & Sign. ${ }^{1}$ & Mean diff. (95\%CI) & Sign. & Sign. ${ }^{1}$ \\
\hline \multicolumn{9}{|l|}{ MDI } \\
\hline & $10.7(7.6)$ & $9.5(7.5)$ & $-0.62(-1.63 ; 0.38)$ & 0.2209 & & $-0.57(-1.62 ; 0.48)$ & 0.2872 & \\
\hline \multicolumn{9}{|l|}{ Trimester } \\
\hline $1^{\text {st }}$ trimester & $11.8(8.1)$ & $14.6(8.1)$ & $2.83(-0.04 ; 5.71)$ & 0.0535 & 0.0339 & $3.16(0.26 ; 6.06)$ & 0.0327 & 0.0253 \\
\hline $2^{\text {nd }}$ trimester & $10.0(7.5)$ & $8.6(6.7)$ & $-1.28(-2.51 ;-0.04)$ & 0.0426 & & $-1.16(-2.50 ; 0.18)$ & 0.0895 & \\
\hline $3^{\text {rd }}$ trimester & $10.3(7.0)$ & $9.7(8.3)$ & $-0.51(-2.42 ; 1.40)$ & 0.6011 & & $-0.95(-2.86 ; 0.97)$ & 0.3318 & \\
\hline \multicolumn{9}{|c|}{ Chronic lung disease } \\
\hline No & $10.7(7.6)$ & $9.6(7.6)$ & $-0.56(-1.60 ; 0.49)$ & 0.2981 & 0.6421 & $-0.49(-1.58 ; 0.60)$ & 0.3820 & 0.2917 \\
\hline Yes & $10.9(7.6)$ & $9.0(5.9)$ & $-1.40(-4.81 ; 2.01)$ & 0.4210 & & $-2.62(-6.45 ; 1.20)$ & 0.1792 & \\
\hline \multicolumn{9}{|c|}{ Psychiatric disorder } \\
\hline No & $10.3(7.4)$ & $9.4(7.2)$ & $-0.38(-1.40 ; 0.64)$ & 0.4678 & 0.0966 & $-0.31(-1.40 ; 0.77)$ & 0.5708 & 0.0202 \\
\hline Yes & $15.4(9.1)$ & $11.0(10.8)$ & $-3.68(-7.44 ; 0.08)$ & 0.0551 & & $-5.29(-9.34 ;-1.23)$ & 0.0106 & \\
\hline \multicolumn{9}{|c|}{ Fertility treatment } \\
\hline No & $10.7(7.7)$ & $12.5(9.2)$ & $-0.48(-1.56 ; 0.59)$ & 0.3775 & 0.1298 & $-0.38(-1.49 ; 0.74)$ & 0.5082 & 0.1629 \\
\hline Yes & $10.8(7.0)$ & $9.6(7.6)$ & $-3.06(-6.21 ; 0.10)$ & 0.0576 & & $-2.75(-5.88 ; 0.39)$ & 0.0861 & \\
\hline \multicolumn{9}{|c|}{ Children living at home } \\
\hline No & $10.8(7.6)$ & $9.4(7.7)$ & $-0.78(-2.32 ; 0.77)$ & 0.3232 & 0.7589 & $-1.15(-2.75 ; 0.46)$ & 0.1607 & 0.4145 \\
\hline Yes & $10.7(7.6)$ & $9.7(7.4)$ & $-0.46(-1.80 ; 0.88)$ & 0.5008 & & $-0.27(-1.65 ; 1.12)$ & 0.7042 & \\
\hline \multicolumn{9}{|l|}{ Given birth } \\
\hline No & $10.7(7.5)$ & $9.4(7.7)$ & $-0.74(-2.24 ; 0.76)$ & 0.3323 & 0.9070 & $-0.93(-2.46 ; 0.60)$ & 0.2336 & 0.6170 \\
\hline One & $10.8(7.6)$ & $9.3(6.8)$ & $-0.89(-2.42 ; 0.64)$ & 0.2547 & & $-0.66(-2.25 ; 0.93)$ & 0.4163 & \\
\hline Multiple & $10.6(8.0)$ & $9.8(9.3)$ & $-0.09(-3.29 ; 3.11)$ & 0.9557 & & $0.94(-2.47 ; 4.36)$ & 0.5880 & \\
\hline \multicolumn{9}{|c|}{ Previous abortions } \\
\hline No & $10.3(7.3)$ & $9.5(7.3)$ & $-0.18(-1.46 ; 1.11)$ & 0.7868 & 0.3411 & $-0.27(-1.59 ; 1.05)$ & 0.6911 & 0.4502 \\
\hline One & $11.3(8.0)$ & $9.6(7.9)$ & $-1.32(-3.32 ; 0.67)$ & 0.1937 & & $-0.75(-2.85 ; 1.36)$ & 0.4870 & \\
\hline Multiple & $11.4(8.2)$ & $8.4(7.2)$ & $-2.26(-5.14 ; 0.62)$ & 0.1234 & & $-2.37(-5.36 ; 0.63)$ & 0.1215 & \\
\hline
\end{tabular}


Table III: Anxiety symptoms assessed by Anxiety Symptom Scale (ASS-score) in the COVID-19 lockdown cohort compared to the control cohort form 2016.

\begin{tabular}{|c|c|c|c|c|c|c|c|c|}
\hline & $\begin{array}{r}\text { Control cohort from } 2016 \\
\text { Mean (SD) }\end{array}$ & $\begin{array}{r}\text { COVID-19 lockdown cohort } \\
\text { Mean (SD) }\end{array}$ & $\begin{array}{c}\text { Unadjusted } \\
\text { Mean diff. (95\%CI) }\end{array}$ & Sign. & Sign. $^{1}$ & $\begin{array}{l}\text { Adjusted } \\
\text { Mean diff. (95\%CI) }\end{array}$ & Sign. & Sign. ${ }^{1}$ \\
\hline \multicolumn{9}{|l|}{ Trimester } \\
\hline $1^{\text {st }}$ trimester & $3.4(4.6)$ & $7.0(6.1)$ & $3.56(1.91 ; 5.20)$ & $<.0001$ & 0.0079 & $4.00(2.37 ; 5.64)$ & $<.0001$ & 0.0004 \\
\hline $2^{\text {nd }}$ trimester & $3.1(4.3)$ & $4.0(4.3)$ & $0.92(0.22 ; 1.62)$ & 0.0104 & & $0.60(-0.15 ; 1.36)$ & 0.1165 & \\
\hline $3^{\text {rd }}$ trimester & $2.9(3.9)$ & $4.9(5.0)$ & $1.99(0.90 ; 3.07)$ & 0.0003 & & $2.05(0.97 ; 3.13)$ & 0.0002 & \\
\hline \multicolumn{9}{|l|}{ Chronic lung disease } \\
\hline No & $3.1(4.3)$ & $4.5(4.7)$ & $1.44(0.84 ; 2.03)$ & $<.0001$ & 0.6257 & $1.30(0.68 ; 1.91)$ & $<.0001$ & 0.2916 \\
\hline Yes & $3.2(4.0)$ & $5.0(6.0)$ & $1.93(0.02 ; 3.85)$ & 0.0476 & & $2.47(0.37 ; 4.58)$ & 0.0213 & \\
\hline \multicolumn{9}{|l|}{ Psychiatric disorder } \\
\hline No & $2.9(4.0)$ & $4.4(4.6)$ & $1.60(1.02 ; 2.18)$ & $<.0001$ & 0.1607 & $1.53(0.91 ; 2.14)$ & $<.0001$ & 0.0938 \\
\hline Yes & $6.3(6.2)$ & $6.2(6.6)$ & $0.05(-2.03 ; 2.14)$ & 0.9611 & & $-0.44(-2.67 ; 1.78)$ & 0.6956 & \\
\hline \multicolumn{9}{|l|}{ Fertility treatment } \\
\hline No & $3.1(4.3)$ & $4.6(4.6)$ & $1.28(0.67 ; 1.89)$ & $<.0001$ & 0.0519 & $1.18(0.55 ; 1.81)$ & 0.0002 & 0.0625 \\
\hline Yes & $3.2(4.2)$ & $6.3(6.0)$ & $3.14(1.37 ; 4.92)$ & 0.0005 & & $2.94(1.20 ; 4.68)$ & 0.0009 & \\
\hline \multicolumn{9}{|c|}{ Children living at home } \\
\hline No & $3.2(4.3)$ & $4.7(5.2)$ & $1.56(0.68 ; 2.43)$ & 0.0005 & 0.7792 & $1.33(0.43 ; 2.23)$ & 0.0039 & 0.8710 \\
\hline Yes & $3.1(4.3)$ & $4.4(4.5)$ & $1.39(0.63 ; 2.15)$ & 0.0004 & & $1.43(0.65 ; 2.21)$ & 0.0003 & \\
\hline \multicolumn{9}{|l|}{ Given birth } \\
\hline No & $3.2(4.2)$ & $4.8(5.5)$ & $1.72(0.87 ; 2.58)$ & $<.0001$ & 0.5114 & $1.57(0.71 ; 2.43)$ & 0.0004 & 0.7514 \\
\hline One & $3.2(4.5)$ & $4.5(4.2)$ & $1.42(0.55 ; 2.29)$ & 0.0014 & & $1.29(0.39 ; 2.19)$ & 0.0051 & \\
\hline Multiple & $3.0(4.0)$ & $3.4(3.7)$ & $0.54(-1.28 ; 2.37)$ & 0.5601 & & $0.81(-1.13 ; 2.74)$ & 0.4131 & \\
\hline \multicolumn{9}{|l|}{ Previous abortion } \\
\hline No & $2.9(4.1)$ & $4.5(4.7)$ & $1.69(0.96 ; 2.42)$ & $<.0001$ & 0.6446 & $1.61(0.86 ; 2.36)$ & $<.0001$ & 0.6193 \\
\hline One & $3.6(4.8)$ & $4.8(4.4)$ & $1.26(0.12 ; 2.40)$ & 0.0301 & & $1.08(-0.11 ; 2.27)$ & 0.0746 & \\
\hline Multiple & $3.4(4.1)$ & $4.2(6.0)$ & $0.95(-0.68 ; 2.57)$ & 0.2534 & & $0.88(-0.78 ; 2.55)$ & 0.2998 & \\
\hline
\end{tabular}


Table IV: Items from the Anxiety Symptom Scale in the COVID-19 lockdown cohort compared to the control cohort from 2016 in relation to the trimester of pregnancy.

\begin{tabular}{|c|c|c|c|c|c|c|c|c|}
\hline & $\begin{array}{r}\text { Control cohort from } 2016 \\
\text { Mean (SD) } \\
\end{array}$ & $\begin{array}{r}\text { Covid-19 lockdown cohort } \\
\text { Mean (SD) }\end{array}$ & $\begin{array}{c}\text { Unadjusted } \\
\text { Mean diff. (95\%CI) }\end{array}$ & Sign. & Sign. ${ }^{1}$ & $\begin{array}{c}\text { Adjusted } \\
\text { Mean diff. (95\%CI) }\end{array}$ & Sign. & Sign. ${ }^{1}$ \\
\hline \multicolumn{9}{|c|}{ A1 Nervousness, tension or inner unrest? } \\
\hline & $1.1(1.1)$ & $1.5(1.1)$ & $0.44(0.30 ; 0.59)$ & $<.0001$ & \multirow{4}{*}{0.0336} & $0.44(0.29 ; 0.60)$ & $<.0001$ & \multirow{4}{*}{0.0082} \\
\hline $1^{\text {st }}$ trimester & $1.3(1.2)$ & $2.2(1.3)$ & $0.96(0.53 ; 1.39)$ & $<.0001$ & & $1.06(0.62 ; 1.50)$ & $<.0001$ & \\
\hline $2^{\text {nd }}$ trimester & $1.0(1.1)$ & $1.4(1.0)$ & $0.35(0.17 ; 0.53)$ & 0.0001 & & $0.31(0.11 ; 0.51)$ & 0.0026 & \\
\hline $3^{\text {rd }}$ trimester & $1.1(1.0)$ & $1.5(1.2)$ & $0.45(0.17 ; 0.73)$ & 0.0018 & & $0.47(0.18 ; 0.75)$ & 0.0014 & \\
\hline \multicolumn{9}{|c|}{ A2 Worrying too much about even the most insignificant things in your daily life? } \\
\hline & $0.7(1.0)$ & $1.0(1.2)$ & $0.25(0.11 ; 0.39)$ & 0.0003 & \multirow{4}{*}{0.0111} & $0.24(0.10 ; 0.39)$ & 0.0012 & \multirow{4}{*}{0.0054} \\
\hline $1^{\text {st }}$ trimester & $0.8(1.1)$ & $1.6(1.0)$ & $0.76(0.36 ; 1.17)$ & 0.0002 & & $0.80(0.39 ; 1.21)$ & 0.0001 & \\
\hline $2^{\text {nd }}$ trimester & $0.7(1.0)$ & $0.8(1.1)$ & $0.12(-0.05 ; 0.29)$ & 0.1587 & & $0.09(-0.10 ; 0.27)$ & 0.3660 & \\
\hline $3^{\text {rd }}$ trimester & $0.7(1.0)$ & $1.1(1.3)$ & $0.34(0.07 ; 0.60)$ & 0.0107 & & $0.33(0.06 ; 0.60)$ & 0.0157 & \\
\hline \multicolumn{9}{|c|}{ A3 Having to avoid certain things, places or activities as anxiety-provoking? } \\
\hline & $0.2(0.7)$ & $1.0(1.5)$ & $0.83(0.73 ; 0.93)$ & $<.0001$ & \multirow{4}{*}{$<.0001$} & $0.79(0.68 ; 0.89)$ & $<.0001$ & \multirow{4}{*}{$<.0001$} \\
\hline $1^{\text {st }}$ trimester & $0.2(0.7)$ & $1.4(1.8)$ & $1.16(0.87 ; 1.45)$ & $<.0001$ & & $1.28(1.00 ; 1.57)$ & $<.0001$ & \\
\hline $2^{\text {nd }}$ trimester & $0.2(0.7)$ & $0.9(1.4)$ & $0.67(0.54 ; 0.79)$ & $<.0001$ & & $0.54(0.41 ; 0.67)$ & $<.0001$ & \\
\hline $3^{\text {rd }}$ trimester & $0.2(0.6)$ & $1.3(1.6)$ & $1.08(0.89 ; 1.26)$ & $<.0001$ & & $1.09(0.90 ; 1.28)$ & $<.0001$ & \\
\hline \multicolumn{9}{|c|}{ A4 Incipient anxiety attacks (panic)? } \\
\hline & $0.1(0.4)$ & $0.2(0.5)$ & $0.05(-0.01 ; 0.11)$ & 0.0747 & \multirow{4}{*}{0.0097} & $0.03(-0.03 ; 0.09)$ & 0.3127 & \multirow{4}{*}{0.0005} \\
\hline $1^{\text {st }}$ trimester & $0.1(0.4)$ & $0.4(0.6)$ & $0.30(0.13 ; 0.47)$ & 0.0007 & & $0.35(0.18 ; 0.52)$ & $<.0001$ & \\
\hline $2^{\text {nd }}$ trimester & $0.1(0.5)$ & $0.2(0.6)$ & $0.04(-0.04 ; 0.11)$ & 0.3322 & & $-0.02(-0.09 ; 0.06)$ & 0.7023 & \\
\hline $3^{\text {rd }}$ trimester & $0.1(0.4)$ & $0.1(0.3)$ & $-0.01(-0.12 ; 0.10)$ & 0.8807 & & $-0.01(-0.12 ; 0.11)$ & 0.9432 & \\
\hline \multicolumn{9}{|c|}{ A5 Actual anxiety attacks? } \\
\hline & $0.0(0.3)$ & $0.1(0.4)$ & $0.02(-0.01 ; 0.06)$ & 0.2243 & \multirow{4}{*}{0.8292} & $0.01(-0.03 ; 0.04)$ & 0.6966 & \multirow{4}{*}{0.7410} \\
\hline $1^{\text {st }}$ trimester & $0.0(0.3)$ & $0.1(0.3)$ & $0.03(-0.08 ; 0.13)$ & 0.6088 & & $0.04(-0.06 ; 0.15)$ & 0.3917 & \\
\hline $2^{\text {nd }}$ trimester & $0.0(0.2)$ & $0.1(0.4)$ & $0.03(-0.02 ; 0.07)$ & 0.2061 & & $0.00(-0.05 ; 0.05)$ & 0.9764 & \\
\hline $3^{\text {rd }}$ trimester & $0.0(0.3)$ & $0.0(0.3)$ & $0.00(-0.06 ; 0.07)$ & 0.9108 & & $0.00(-0.06 ; 0.07)$ & 0.8903 & \\
\hline \multicolumn{9}{|c|}{ A6 Recurrent, unpleasant compulsive thoughts that won't stop? } \\
\hline & $0.1(0.5)$ & $0.2(0.5)$ & $0.02(-0.04 ; 0.09)$ & 0.5356 & \multirow{3}{*}{0.3385} & $0.01(-0.06 ; 0.08)$ & 0.7621 & \multirow{3}{*}{0.1187} \\
\hline $1^{\text {st }}$ trimester & $0.2(0.5)$ & $0.3(0.7)$ & $0.10(-0.09 ; 0.29)$ & 0.2912 & & $0.13(-0.07 ; 0.32)$ & 0.1964 & \\
\hline $2^{\text {na }}$ trimester & $0.2(0.5)$ & $0.2(0.5)$ & $-0.02(-0.10 ; 0.07)$ & 0.7136 & & $-0.05(-0.13 ; 0.04)$ & 0.3020 & \\
\hline
\end{tabular}


A7 Having to check everything you do again and again?

$\begin{array}{lllll}1^{\text {st }} \text { trimester } & 0.1(0.5) & 0.1(0.5) & -0.01(-0.08 ; 0.06) & 0.7635 \\ 2^{\text {nd }} \text { trimester } & 0.1(0.5) & 0.1(0.4) & -0.02(-0.21 ; 0.17) & 0.8570 \\ 3^{\text {rd }} \text { trimester } & 0.1(0.5) & 0.1(0.4) & -0.03(-0.11 ; 0.05) & 0.4539 \\ & 0.1(0.5) & 0.2(0.7) & 0.04(-0.08 ; 0.17) & 0.4889\end{array}$

0.6018

$-0.01(-0.08 ; 0.07)$

0.8838 $-0.01(-0.21 ; 0.19) \quad 0.9170$ $-0.02(-0.11 ; 0.07) \quad 0.6613$ $0.05(-0.08 ; 0.19) \quad 0.4097$

A8 Feeling very shy in company, for example when eating in front of other people?

$\begin{array}{llll}1^{\text {st }} \text { trimester } & 0.2(0.5) & 0.1(0.4) & -0.10(-0.17 ;-0.03) \\ 2^{\text {nd }} \text { trimester } & 0.2(0.5) & 0.1(0.4) & -0.10(-0.30 ; 0.10) \\ 3^{\text {rd }} \text { trimester } & 0.2(0.5) & 0.0(0.3) & -0.12(-0.21 ;-0.03) \\ & 0.2(0.6) & 0.1(0.4) & -0.06(-0.20 ; 0.07)\end{array}$

0.0045

0.3357

0.0081

0.3616

0.7860

$-0.10(-0.18 ;-0.03) \quad 0.0070$ $-0.09(-0.30 ; 0.11) \quad 0.3733$ $-0.12(-0.22 ;-0.03) \quad 0.0112$

A9 Had recurrent thoughts or memories of a very violent experience?

$\begin{array}{lll}1^{\text {st }} \text { trimester } & 0.2(0.6) & 0.1(0.5) \\ 2^{\text {nd }} \text { trimester } & 0.3(0.7) & 0.3(0.8) \\ 3^{\text {rd }} \text { trimester } & 0.2(0.6) & 0.1(0.3) \\ & 0.2(0.6) & 0.1(0.5)\end{array}$

$-0.09(-0.17 ;-0.00)$ $0.03(-0.21 ; 0.27)$

0.0411

0.1930

0.0343

0.3405

$-0.06(-0.20 ; 0.07)$

0.3723

A10 Difficulty performing your daily activities because of these symptoms?

$-0.08(-0.23 ; 0.08)$

$-0.07(-0.16 ; 0.02) \quad 0.1331$ $0.06(-0.18 ; 0.31) \quad 0.6204$ $-0.10(-0.21 ; 0.01) \quad 0.0774$ $-0.05(-0.21 ; 0.11) \quad 0.5315$

0.4636

0.0115

$1^{\text {st }}$ trimester

$0.2(0.7)$

$0.2(0.8)$

$0.03(-0.05 ; 0.12)$

$0.2(0.7)$

$0.33(0.07 ; 0.58)$

trimester

$0.1(0.5)$

$0.2(0.7)$

$-0.04(-0.14 ; 0.07)$

0.5196

0.4039

0.5456

$0.05(-0.04 ; 0.14) \quad 0.2973$

0.0301

$0.38(0.13 ; 0.64) \quad 0.0033$

$-0.03(-0.15 ; 0.08) \quad 0.5758$

$0.08(-0.09 ; 0.24) \quad 0.3763$ 